Article

\title{
Speed Responses to Speed Humps as Affected by Time of Day and Light Conditions on a Residential Road with Light-Emitting Diode (LED) Road Lighting
}

\author{
Annika K. Jägerbrand ${ }^{1, *(\mathbb{D})}$, Maria Johansson ${ }^{2}$ and Thorbjörn Laike ${ }^{2}$ \\ 1 Calluna AB, Hästholmsvägen 28, 13130 Nacka, Sweden \\ 2 Environmental Psychology, Department of Architecture and Built Environment, Lund University, \\ 22100 Lund, Sweden; maria.johansson@arkitektur.lth.se (M.J.); thorbjorn.laike@arkitektur.lth.se (T.L.) \\ * Correspondence: annika.jagerbrand@calluna.se; Tel.: +46-703-493-806
}

Received: 3 January 2018; Accepted: 7 March 2018; Published: 13 March 2018

\begin{abstract}
The speed-reducing effect of speed humps during darkness is important to ensure a consistent speed reduction and a decreased probability of accidents during darkness. This study examined the effects of speed humps, compared with a control location, on a residential road in Sweden with light-emitting diode (LED) street lighting and a $30 \mathrm{~km} / \mathrm{h}$ posted speed limit. Hypotheses tested were that: (I) vehicle speed is higher during daylight than in darkness; (II) speed at speed humps is lower than at control locations during both daylight and darkness; (III) speed at humps is higher during daylight; (IV) vehicle speed at humps is lower when luminance or visibility of the humps is greater; and, (V) the road environment of speed humps is perceived as being similar by drivers. The results showed that vehicle speed at the control location was negligibly higher $(+0.3 \mathrm{~km} / \mathrm{h})$ during daylight than in darkness. Speed humps reduced driving speed by $20 \%$ when compared with the posted speed limit and the effect was not significantly different between daylight and darkness. Speed reduction for the three speed humps varied between $9 \%$ and $29 \%$ as compared with the posted speed limit. In this study, the LED road lighting that was placed directly above or in front of the hump achieved the highest luminance. This study could not reveal any significant differences in vehicle speed attributable to light conditions per se.
\end{abstract}

Keywords: speed-reduction; measures; street; lighting; day; night; traffic calming

\section{Introduction}

Since the establishment of the new safety paradigm (Vision Zero) in Sweden in 1997, traffic safety policy has focused on road redesign, lower vehicle speed, and managing the kinetic energy from collisions in such a way that fatalities and serious injuries are zero (e.g., [1]). Consequently, much effort has been devoted to increasing safety for all of the categories of road users. One of the main factors is reducing vehicle speed, especially in potential conflict areas between vehicles and vulnerable road users (i.e., pedestrians, cyclists, joggers). Pedestrian mortality increases dramatically between a vehicle speed of $30 \mathrm{~km} / \mathrm{h}$, where most pedestrians survive, and $50 \mathrm{~km} / \mathrm{h}$, where most pedestrians are killed [1-3]. As a general rule, vulnerable road users should therefore not be exposed to vehicular traffic driving at speeds exceeding $30 \mathrm{~km} / \mathrm{h}$. In Sweden, roads with vulnerable road users consequently have a maximum speed limit of $30 \mathrm{~km} / \mathrm{h}$ and commonly include additional speed-reducing designs, for example, narrow lanes, speed humps, or speed bumps to further reduce vehicle speeds to below $30 \mathrm{~km} / \mathrm{h}$.

Speed humps function as passive traffic-calming devices and they consist of less abrupt and longer (4000-8000 $\mathrm{mm}$ ) raised road areas than speed bumps (e.g., [4]). Speed bumps are shorter $(600-1200 \mathrm{~mm})$ and have a circular or parabolic shape, whereas speed humps may have a variety of 
shapes [4]. Both types have approximately the same height and are constructed across the street to reduce vehicle speed. Speed humps are deployed on residential and local streets and in midblock areas and generally reduce speed by an average of 20-25\%, but the actual speed reduction depends on many factors, such as hump height and spacing [5-7], and may vary between sites [8]. For example, speed humps have been shown to reduce speed by $43-63 \%$ on residential roads with a posted speed limit of $40 \mathrm{~km} / \mathrm{h} \mathrm{[5]} \mathrm{and} \mathrm{to} \mathrm{have} \mathrm{varying} \mathrm{effects,} \mathrm{from} \mathrm{reducing} \mathrm{speed} \mathrm{by} 39 \%$ to increasing speed by $4 \%$, on roads with various posted speed limits [8]. The speed-reducing effects of speed humps and bumps have been thoroughly studied and modelled in previous research (e.g., [4,9-12]). Speed humps have also been proven to be effective in reducing the number of collisions between motor vehicles and pedestrians, especially children $[13,14]$.

Despite being of great importance in reducing collisions, the speed-reducing effects of speed humps during the hours of darkness are more or less unknown since aspects of light has not been included in previous studies. In many countries, especially those that are situated at higher latitudes, such as in Scandinavia, there are very few daylight hours during autumn, winter, and early spring. Therefore, during these seasons the rush hour traffic occurs in darkness and this may indirect cause higher risk of accidents due to higher traffic density during darkness. The speed-reducing effect of speed humps during darkness is therefore important to investigate thoroughly to ensure there is a consistent speed reduction effect and a decreased probability of accidents all year around.

Consequently, the aims of this study were to investigate the speed-reducing effects during daylight and in darkness, of three speed humps in different road lighting conditions, when compared with the driving speed at a control location (a road section similar in design, but without speed humps). The comparison with a control location was essential since there is a lack of studies on normal speed responses comparing daylight and darkness responses during similar conditions as this study, i.e., residential areas.

The risk of road accidents increases significantly with darkness [15-18]. In particular, the risk of pedestrian fatalities has been shown to increase by about seven-fold with darkness [19]. Thus, installing and maintaining adequate road lighting may decrease the number of fatal accidents, as well as accidents involving injuries (see e.g., [20,21]). Comparisons of vehicle speed between daylight and darkness conditions show mixed outcomes, for example, higher speeds in daylight [22,23], lower in daylight [24], or no difference [25]. In an intervention study, road lighting was shown to increase vehicle speed by approximately $3 \%$ as compared with unlit sections and by $5 \%$ compared with control sections [23]. Bassani and Mutani [24] also found that driving speeds were significantly influenced by illuminating the road. However, a study of almost 60 million vehicle passes at 25 locations investigated vehicle speed between daylight, twilight, and darkness, with and without road lighting, and did not reveal any significant differences in speed attributable to light conditions [26]. Despite the well-established fact that darkness reduces traffic safety, especially for pedestrians and children, very few studies have investigated vehicle speed responses under various light conditions, and even fewer have investigated the effects of traffic calming measures, such as speed responses under such various light conditions.

Yet, road lighting is very common on roads with speed-reducing measures and is used for traffic safety purposes as well as for human perception of social and safety aspects. Light-emitting diodes (LED) are a new light source already being widely applied in road lighting on residential, local streets, and pedestrian and bicycle lanes (e.g., $[27,28])$. However, due to their higher luminance and smaller size, there are serious concerns about glare when using LEDs in road lighting (e.g., [29]). Discomfort glare increases the contrast and makes it more difficult to see the (dark) background from the line of sight, resulting in lower visibility for drivers. Thus, when designing LED road lighting in combination with speed-reducing measures, it is important to ensure that the measures are fully visible. It could be argued that road lights should be situated directly above or in front of speed humps to give maximum illumination of the raised hump surface, but the light conditions will also vary depending on road light height and distance. Consequently, while speed-reducing measures may reduce the risk of accidents, 
it is not known whether the speed-reducing effect in residential areas is significantly affected by daylight, darkness, or artificial light conditions, such as LED road lighting.

Additionally, the speed-reducing effects of speed humps may also be modified by several other factors, such as visibility or how drivers experience the road environment. Therefore, in this study, the road environment of the humps was evaluated by measuring the luminance and by performing a separate Semantic Environmental Description (SED) analysis. SED is a tool based on semantic differentials for examining how a person experiences a certain environment in terms of eight dimensions: perceived pleasantness, complexity, unity, enclosedness, potency, affection, originality, and social status [30].

The following hypotheses were tested:

(I) Vehicle speed is higher during daylight than in darkness.

(II) Vehicle speed at speed humps is lower than at control locations during both daylight and darkness.

(III) Speed at humps is higher during daylight.

(IV) Speed at humps is lower when luminance (visibility) of the humps is greater.

(V) The road environment of speed humps is perceived as being similar by drivers.

\section{Materials and Methods}

This study investigated vehicle speed at four different locations (one control and three hump locations), using fixed radar equipment, during daylight and darkness (i.e., artificial LED road light) on a residential road with a posted speed limit of $30 \mathrm{~km} / \mathrm{h}$ in a suburb of Stockholm. The speed humps were situated at different distances from LED road lights $(58 \mathrm{~W})$, giving different luminance levels for the oncoming traffic. The SED analysis was performed as an internet-based questionnaire based on digital photographs.

\subsection{Site Description}

The study area was Vreta Gårds väg, in Vretarna, which is a residential suburb of Stockholm. The road has a posted speed limit of $30 \mathrm{~km} / \mathrm{h}$ and four speed humps at different distances from each other (Figure 1), one of which (situated between Humps 1 and 2) was not used for speed measurements. These speed humps are 6-8 $\mathrm{m}$ in length and $10 \mathrm{~cm}$ high and have squares $(50 \mathrm{~cm} \times 50 \mathrm{~cm})$ of reflective paint in two rows in each direction (Figure 2). The distance between the control location and Hump 1 is approximately $106 \mathrm{~m}$, between Humps 1 and 2, $186 \mathrm{~m}$ and between Humps 2 and 3, $168 \mathrm{~m}$. The traffic along the road is mainly residential traffic, commuters going to work/school and residents driving to/from recreational activities. There is a school that is situated between Humps 1 and 2. At the time of measurements, the traffic flow on the road (in the period 4-10 November 2014) was 850-1100 vehicles per day.

Weather data (temperature at the road surface and precipitation type: none, rain, snow, or sleet) were collected from three automatic weather stations run by the Swedish Transport Administration, situated at 3, 4, and $5.6 \mathrm{~km}$ distance from Vreta Gårds väg, and mean values were calculated. During the measurement period, 4-15 November 2014, sunrise took place between 07:15 and 07:42, and sunset between 15:48 and 15:23. 


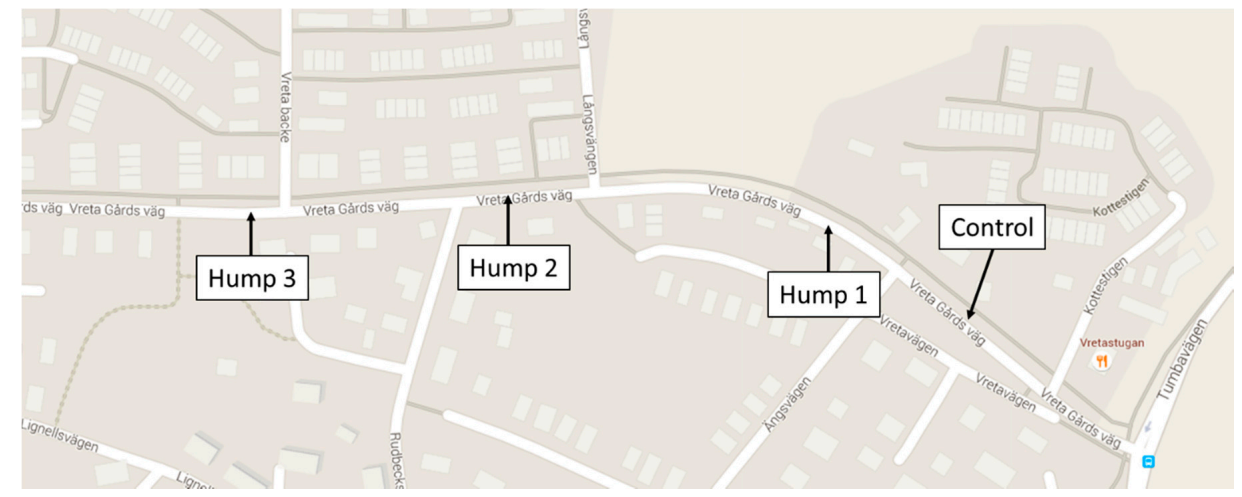

Figure 1. Map of Vreta Gårds väg, Stockholm, Sweden, showing the location of the three hump measurement sites and the control measurement site. Map data @2016 Google.

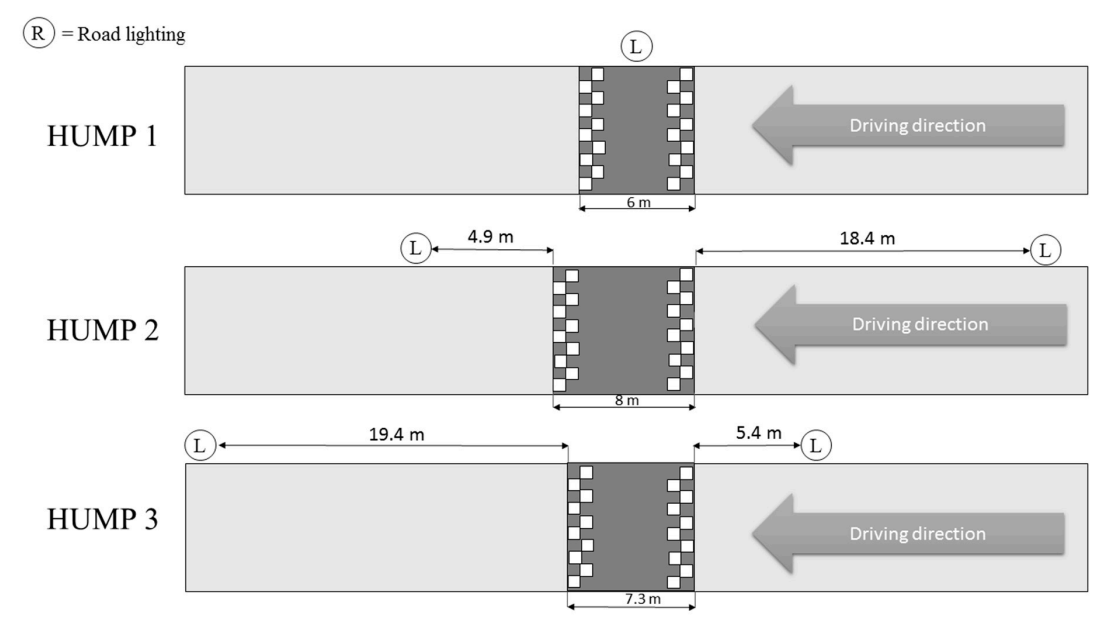

Figure 2. Overview of the location of road lights (L) and speed humps (1-3) and their dimensions and distances (not accurate scales).

\subsection{Experimental Design and Speed Measurements}

The control location for speed measurements was located about $100 \mathrm{~m}$ before the first speed hump (see Figure 1). Hump 1 had road lighting situated directly above the hump; Hump 2 had road lighting $18.4 \mathrm{~m}$ before and $4.9 \mathrm{~m}$ after the hump in the driving direction; and, Hump 3 had road lighting $5.4 \mathrm{~m}$ before and $19.4 \mathrm{~m}$ after the hump in the driving direction (Figure 2). Radar equipment (Sierzega SR4) was installed to measure vehicle speed at the control location and at $5 \mathrm{~m}$ before the humps. The radar traffic measuring system has an inconspicuous design and can record every vehicle without disturbing the traffic. Measurements include length of the vehicle, safety margin to the vehicle in front, vehicle speed in two directions, and day and time of the recording. The SR4 records vehicle speed between 2-199 km/h with an accuracy of $\pm 3 \%$. The measurements started on 4 November 2014 and continued until the memory was full or the battery died. This occurred on 10 November at the control location and on 14-15 November at the humps. The average daily traffic at the control location (located at the entrance of the area and prior to the humps) was approximately 800 during the study period.

\subsection{Road Lighting and Light Measurements}

The road lighting for the road consists of $8 \mathrm{~m}$ high street-light poles situated approximately $30 \mathrm{~m}$ apart, installed 2011/2012, and carrying Iridium2 LED (58 W) lights. Colour temperature of the light source is $4125 \mathrm{~K}$ and colour rendering index (CRI) is 78.2. The road lighting automatically turns off at sunrise and on at sunset and is regulated by a timer. The lighting operates with an automatic dimming 
schedule that is applied everywhere except on intersections. The lights are on at $100 \%$ effect except between 19:00-00:00 and 05:00-07:00, when the effect is 80\%, and at night (00:00-05:00), when the effect is $50 \%$. All of the locations in this study except Hump 2 had this dimming schedule applied during the study period.

Measurements of luminance were performed using an LMK Mobile Advanced imaging luminance photometer and LMK Labsoft laboratory software (Techno Team Bildverarbeitung GmbH, ver. 12.7.23). The LMK Mobile Advanced device is based on a Canon EOS 550D camera. Photos were taken at $10 \mathrm{~m}$ distance from the humps in the driving direction and at a height of $150 \mathrm{~cm}$, with and without flashlights on the ground to mark the corners of the humps. LMK Labsoft was used to extract the measured data. Mean luminance was calculated for the whole hump area. LMK Mobile Advanced luminance measurements were calibrated against values of luminance from a Jeti Specbos 1201 spectro-radiometer measured against a white surface below the road light. The luminance measurements showed that mean luminance of the speed hump area was $0.93,0.60$ and $0.70 \mathrm{~cd} / \mathrm{m}^{2}$ for Humps 1, 2, and 3, respectively (Figure 3). Luminance measurements were not included in statistical analyses but were used to describe the light environment and to evaluate visibility of humps in the discussion.

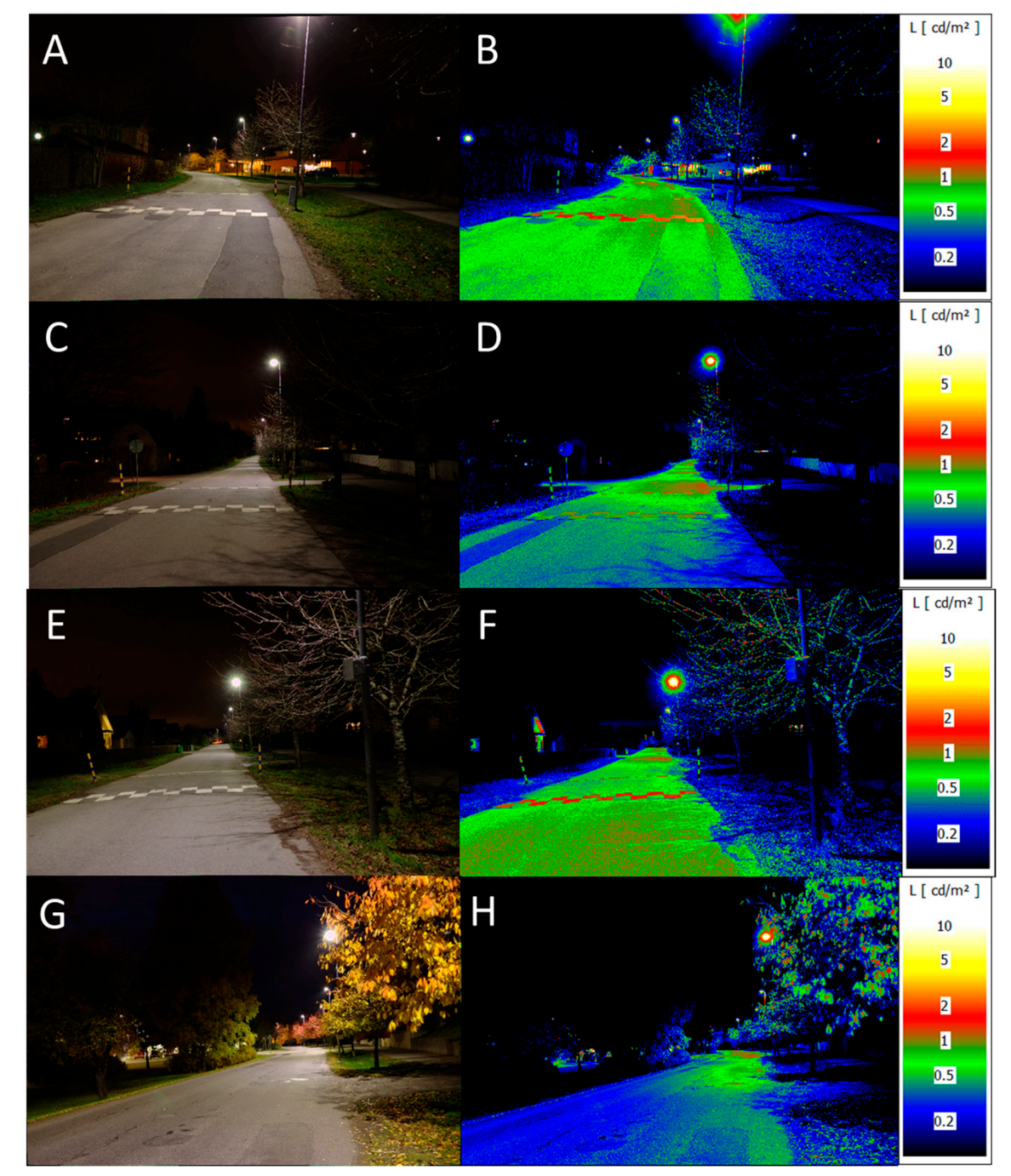

Figure 3. Photos and luminance photos of bumps and control location. Photographs (A-F) were taken on 15 November 2014 between 17:00-19:00 and photos (G-H) (control location) on 24 October 2015 at 18:30. All of the photos were taken with a Canon EOS 550D (with Sigma lens 18-50 mm, F2,8, iso 100) $150 \mathrm{~cm}$ above the ground on a tripod. 


\subsection{Semantic Description of Environments}

SED was used in combination with speed measurements and luminance to fully evaluate underlying differences between the hump environments. It was assumed that the road environment of each speed hump was perceived by drivers to be approximately similar, and therefore did not significantly influence how they experienced the road environment (measured by SED) or their driving behaviour (measured by speed).

To analyse whether the road environment of speed humps was perceived as similar by drivers, an SED analysis was carried out using an internet-based version of the SED involving photographs of each hump (Figure 3). Forty participants were asked to complete a questionnaire assessing each one of the three environments. The items and methodology used in the questionnaire to calculate the eight dimensions followed Küller [30]. The humps were presented in three different orders of presentation (order 1 (Humps 1, 2, 3): $n=10$, order 2 (Humps 3, 2, 1): $n=17$, order 3 (Humps 2, 3, 1): $n=13$ ).

\subsection{Data Analyses}

Prior to analyses, the speed data were checked for distribution patterns to ensure approximate normal distribution. Vehicle speed can be influenced by vehicles travelling in front. In this study, we ensured that vehicles were flowing freely by only using measurements that had headway $>6 \mathrm{~s}$. This is the minimum headway characterising free-flowing vehicles in urban areas in Sweden [31].

To test hypotheses I-V, vehicle speed and its dependence on humps, daylight, and other factors were analysed by generalised linear models (GLM) testing all of the independent variables separately, jointly, and their interactions in all the possible combinations. Vehicle speed was always the dependent variable. Separate GLMs were conducted on different data subsets, as described below. Akaike's information criterion (AIC) was initially used for evaluating the quality of fit for the models, but the results indicated overfitting and therefore constant AIC (CAIC) was compared with AIC (see [32]). In most cases, AIC showed signs of overfitting and CAIC showed signs of underfitting. We therefore decided to only test the models with the independent variables included as main effects to avoid overfitting (when using interactions between variables) since this could give rise to many false and spurious significances between speed and for example temperature variation. However, except for effects of speed humps between daylight and darkness where both AIC and CAIC showed the lowest values for a specific model. Independent variables were coded as: darkness and daylight $(1=$ darkness, 0 = daylight); road temperature $\left(1=\right.$ above $4{ }^{\circ} \mathrm{C}, 0=$ below $\left.4{ }^{\circ} \mathrm{C}\right)$; and, precipitation type $(0=$ dry, no rain, 1 = wet road, rainy, 2 = snow or sleet). The road temperature was coded as a dummy variable for above and below $4{ }^{\circ} \mathrm{C}$ since there is an increased risk for slipperiness when temperature drops below $4{ }^{\circ} \mathrm{C}$, which may modify driving behaviour. GLM settings were linear link function (GENLIN in SPSS), model effects type III, and Wald chi-square statistics. Maximum likelihood estimate was used for parameter estimation.

First, we tested whether vehicle speed (dependent variable) was lower during the hours of darkness at the control site by performing GLM with the independent variables daylight/darkness, road temperature, and precipitation type. Next, we investigated whether vehicle speed at the speed humps was lower during the hours of darkness than during daylight hours and in comparison with the control site. The data were analysed separately for darkness and daylight hours by GLM and included the independent factors: site (control or the three humps), road temperature, and precipitation type (coded as mentioned above). To investigate whether speed responses (dependent variable) to humps were different between the hours of darkness and daylight, we performed GLM on the data without including speed data from the control site. The independent variables were daylight/darkness, road temperature and precipitation type. Finally, we analysed whether speed responses to the humps were significantly different. Only the data measured at $100 \%$ road lighting were used in that analysis. The independent variables were hump $(1,2,3)$, road temperature, and precipitation type.

To test for significant differences in SED between humps and/or order of presentation, ANOVA (analysis of variance) was performed on each dimension. The data from the questionnaire were 
checked for normal distribution by ensuring that the ratio between skewness/skewness standard error and curtosis/curtosis standard error was $<5$. For social status, log-transformation was used to meet the normal distribution criterion. Two-way ANOVA and the post-hoc Games-Howells pair-wise comparison test were employed to test the effects of humps and order of presentation in the questionnaire as main effects and their interaction effect.

All analyses were performed in IBM @ SPSS @ Statistics version 22 (22.0.0.1.).

\section{Results}

Vehicle speed at the control location was only slightly higher during daylight $(30.1 \mathrm{~km} / \mathrm{h})$ than in the hours of darkness $(29.8 \mathrm{~km} / \mathrm{h})$ (Table 1 and Figure 4$)$. The 85 th percentile for vehicle speed was found to be $36 \mathrm{~km} / \mathrm{h}$ (Table 1). However, there was variation in mean speed depending on time of day, with particularly high vehicle speeds late in the evening and during the night (Figure 4). A large variation in the total number of vehicles per hour during the study period was also found, for example, 20 and 32 vehicles, respectively, for the hours 05:00-05:59 and 06:00-06:59 and 636 vehicles for 18:00-18:59 (for more information, see Figure S1 in Supplementary Materials).

Table 1. Descriptive statistics on the speed $(\mathrm{km} / \mathrm{h})$ of free-flowing vehicles at the control location and at humps, divided by natural light conditions (daylight/darkness). $n=$ number of vehicles, $\mathrm{M}=$ mean value, $\mathrm{SD}=$ standard deviation. 50th and 85 th percentile speeds are also shown.

\begin{tabular}{cccccc}
\hline Location and Natural Light Conditions & $\boldsymbol{n}$ & $\mathbf{M}$ & SD & 50th Percentile & 85th Percentile \\
\hline Control (all) & 4803 & 28.9 & 5.7 & 29.0 & 36.0 \\
Daylight & 1571 & 30.1 & 5.8 & 30.0 & 36.0 \\
Darkness & 3232 & 29.8 & 5.7 & 29.0 & 36.0 \\
Humps (all) & 18252 & 23.7 & 5.4 & 23.0 & 29.0 \\
Daylight & 5392 & 23.8 & 5.4 & 23.0 & 29.0 \\
Darkness & 12860 & 23.6 & 5.4 & 23.0 & 29.0 \\
\hline
\end{tabular}

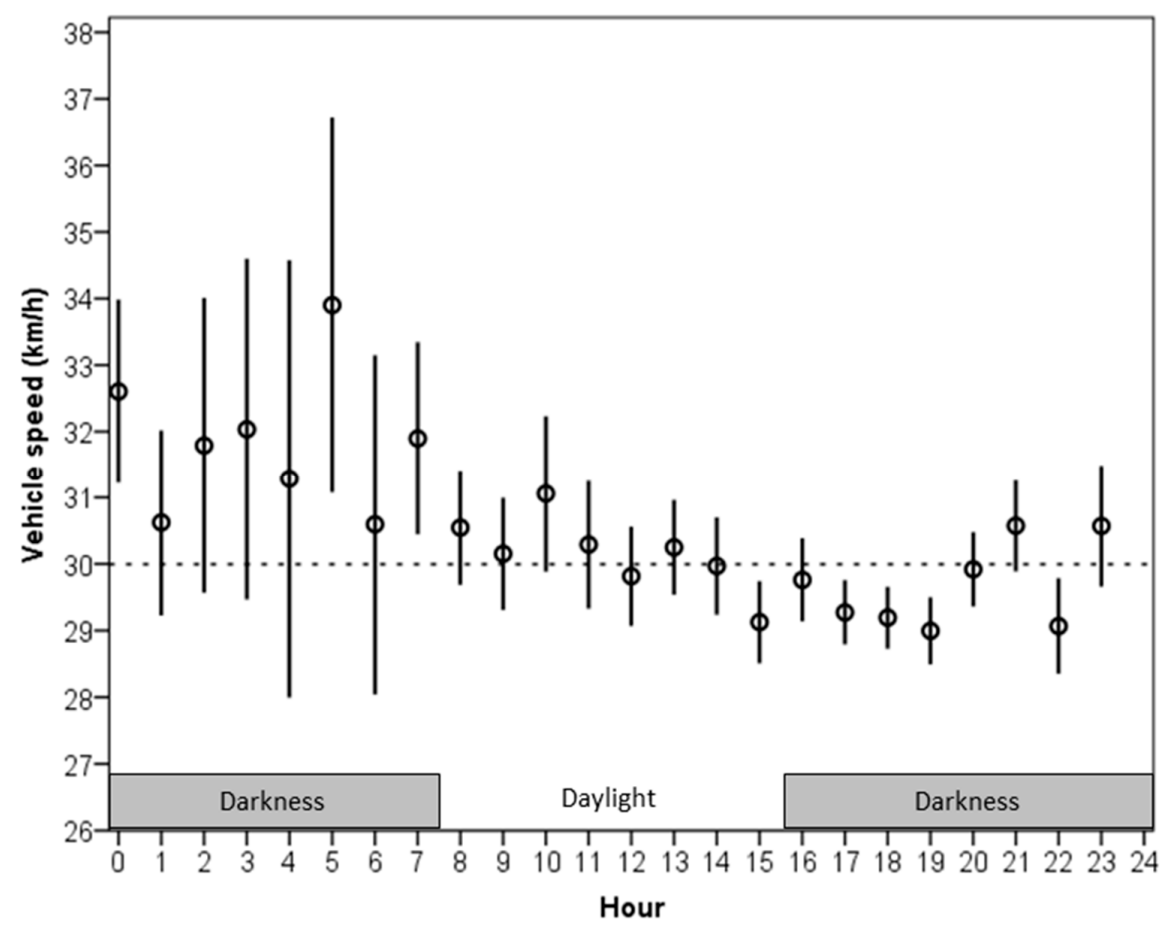

Figure 4. Mean vehicle speed at the control location during the hours of darkness and daylight over a 24-h period. Dotted line shows the posted speed limit (30 km/h). Vertical error bars: $95 \%$ confidence intervals. Measured during 4-10 November 2014 on Vreta Gårds väg in Stockholm, Sweden $(n=4803)$. 
Speed humps had a significant speed-reducing effect during both daylight and darkness hours compared with the control speed (Table 2). The speed-reducing effect of humps was slightly higher during the hours of darkness, resulting in a mean velocity of $23.8 \mathrm{~km} / \mathrm{h}$ in daylight and $23.6 \mathrm{~km} / \mathrm{h}$ in darkness. This represented a speed-reducing effect of $20.7 \%$ in daylight and $21.3 \%$ in darkness as compared with the posted speed limit (Tables 1, 3 and 4). However, when we tested the speed-reducing effects of humps per se, there were no significant differences in speed responses between the hours of daylight and darkness (Table 2). The speed-reducing effect of humps was found to vary between 9 and $30 \%$ (Table 4 ) and differed significantly between the individual humps $(p<0.0001$; Table 2), with Humps 1 and 3 having significantly greater speed-reducing effects $(4.6 \mathrm{~km} / \mathrm{h}$ and $5.8 \mathrm{~km} / \mathrm{h}$, respectively) than Hump 2 (Table 3).

Table 2. Main results from the generalised linear models testing significance of the independent variables for the dependent variable (vehicle speed) for the different models (for more information see data analyses in materials and methods). Parameter estimates from the models are shown in Table 3. Hypothesis questions 1-4 are also shown in the table. $\mathrm{D}=$ Daylight and darkness, $\mathrm{RT}=\mathrm{Road}$ temperature, $\mathrm{P}=$ Precipitation type. $p=$ significance level, $\mathrm{df}=$ degrees of freedom.

\begin{tabular}{llll}
\hline Model Effects & \multicolumn{1}{l}{ Type III } & \\
\hline Source & Wald Chi-Square & df & $p$ \\
\hline Question 1. Is speed higher during & daylight at the control location? & \\
Model: Daylight and darkness & road temperature & precipitation type $(n=4803)$ & \\
(Intercept) & $39,161.44$ & 1 & $<0.001$ \\
Daylight and darkness & 4.01 & 1 & 0.045 \\
Road temperature & 0.78 & 1 & 0.377 \\
Precipitation type & 1.66 & 2 & 0.437 \\
\hline
\end{tabular}

Question 2. Is speed at speed humps lower during daylight and in darkness compared with the control location?

Model: Humps \& control + road temperature + precipitation type ( $n=6963$ daylight; $n=16092$ darkness $)$

Daylight

Humps or control 2527.5

Road temperature $\quad 11.45$

Precipitation type $\quad 21.18$

Darkness

(Intercept)

$\begin{array}{ll}21.18 & 2\end{array}$

$<0.001$
$<0.001$

Humps or control

$83,832.64$

6683.37

Precipitation type

1.48

20.59

0.001

$<0.001$

$<0.001$

$<0.001$

0.224

Question 3. Is the speed-reducing effect of speed humps similar in daylight and darkness?

Model * ${ }^{*}+\mathrm{RT}+\mathrm{P}+\mathrm{D} \times \mathrm{RT}+\mathrm{D} \times \mathrm{P}+\mathrm{RT} \times \mathrm{P}(n=18,252)$

$\begin{array}{llll}\text { (Intercept) } & 40,817.88 & 1 & <0.001\end{array}$

$\begin{array}{llll}\text { Daylight and darkness (D) } & 0.27 & 1 & 0.607\end{array}$

$\begin{array}{llll}\text { Road temperature (RT) } & 3.35 & 1 & 0.067\end{array}$

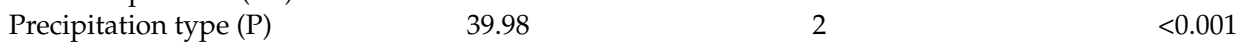

$\begin{array}{llll}\mathrm{D} \times \mathrm{RT} & 10.51 & 1 & 0.001\end{array}$

$\begin{array}{llll}\mathrm{D} \times \mathrm{P} & 6.13 & 1 & 0.001 \\ \mathrm{RT} \times \mathrm{P} & 0.58 & 1 & 0.047\end{array}$

$\begin{array}{llll}\mathrm{RT} \times \mathrm{P} & 0.58 & 1 & 0.445\end{array}$

Question 4. Is the speed-reducing effect of speed humps greater when hump luminance is higher?

Model: Humps + RT + P $(n=5879)$

$\begin{array}{llll}\text { (Intercept) } & 37,688.45 & 1 & <0.001 \\ \text { Humps } & 1351.19 & 2 & <0.001 \\ \text { Road temperature } & 1.63 & 1 & 0.201 \\ \text { Precipitation type } & 13.40 & 2 & 0.001\end{array}$

$\begin{array}{llll}\text { Precipitation type } & 13.40 & 2 & 0.001\end{array}$

${ }^{*}$ Model selected by AIC and CAIC. 
Table 3. Results for the parameter estimates from the generalised linear models for questions 1-4. Significant variables selected are included in the table. For main results of the model testing of influence of the independent variables on the dependent variable (vehicle speed), see Table 2. For questions 2 and 4 , effects of individual humps are shown. $\mathrm{SE}=$ standard error, $p=$ significance level, $\mathrm{df}=$ degrees of freedom.

\begin{tabular}{|c|c|c|c|c|c|c|c|}
\hline \multirow{2}{*}{ Parameter } & \multirow{2}{*}{ B } & \multirow{2}{*}{ SE } & \multicolumn{2}{|c|}{ 95\% Wald Confidence Interval } & \multicolumn{3}{|l|}{ Hypothesis Test } \\
\hline & & & Lower & Upper & Wald Chi-Square & df & $p$ \\
\hline \multicolumn{8}{|c|}{ Question 1. Is speed higher during daylight at the control location? } \\
\hline \multicolumn{8}{|c|}{ Model: Daylight + darkness + road temperature + precipitation type $(n=4803)$} \\
\hline (Intercept) & 29.54 & 0.31 & 28.93 & 30.16 & 8805.57 & 1 & $<0.001$ \\
\hline Daylight & 0.36 & 0.18 & 0.01 & 0.71 & 4.01 & 1 & 0.045 \\
\hline \multirow{3}{*}{\multicolumn{8}{|c|}{$\begin{array}{l}\text { Question 2. Is speed at speed humps lower during daylight and in darkness compared with the control location? } \\
\text { Model: humps and control + road temperature + precipitation type ( } n=6963 \text { daylight; } n=16,092 \text { darkness) } \\
\text { Daylight }\end{array}$}} \\
\hline & & & & & & & \\
\hline & & & & & & & \\
\hline (Intercept) & 28.96 & 0.28 & 28.42 & 29.50 & $10,911.32$ & 1 & $<0.001$ \\
\hline Hump 1 & -7.21 & 0.17 & -7.53 & -6.88 & 1852.42 & 1 & $<0.001$ \\
\hline Hump 3 & -7.98 & 0.20 & -8.37 & -7.59 & 1602.65 & 1 & $<0.001$ \\
\hline Hump 2 & -2.78 & 0.19 & -3.16 & -2.40 & 206.82 & 1 & $<0.001$ \\
\hline Road temperature 0 & 0.56 & 0.17 & 0.24 & 0.89 & 11.45 & 1 & 0.001 \\
\hline Dry & 1.07 & 0.24 & 0.61 & 1.54 & 20.55 & 1 & $<0.001$ \\
\hline Rain & 1.13 & 0.48 & 0.19 & 2.06 & 5.54 & 1 & 0.019 \\
\hline \multicolumn{8}{|l|}{ Darkness } \\
\hline Hump 1 & -7.43 & $\begin{array}{l}0.21 \\
0.11\end{array}$ & $\begin{array}{l}20.94 \\
-7.65\end{array}$ & $\begin{array}{l}29.70 \\
-7.21\end{array}$ & $\begin{array}{l}19,003.52 \\
4306.43\end{array}$ & $\begin{array}{l}1 \\
1\end{array}$ & $<0.001$ \\
\hline Hump 3 & -8.80 & 0.13 & -9.05 & -8.54 & 4612.13 & 1 & $<0.001$ \\
\hline Hump 2 & -2.98 & 0.12 & -3.21 & -2.75 & 629.38 & 1 & $<0.001$ \\
\hline Road temperature 0 & -0.12 & 0.10 & -0.33 & 0.08 & 1.48 & 1 & 0.224 \\
\hline Dry & 0.56 & 0.19 & 0.19 & 0.94 & 8.71 & 1 & 0.003 \\
\hline Rain & -0.09 & 0.27 & -0.62 & 0.44 & 0.12 & 1 & 0.734 \\
\hline
\end{tabular}

Question 3. Not relevant (see text).

Question 4. Is the speed-reducing effect of speed humps greater when hump luminance is higher?

Model: Humps + RT + P $(n=5879)$

\begin{tabular}{llllllll} 
(Intercept) & 26.83 & 0.29 & 26.25 & 27.41 & 8287.86 & 1 & $<0.001$ \\
Hump 1 & -4.59 & 0.15 & -4.88 & -4.30 & 947.21 & 1 & $<0.001$ \\
Hump 3 & -5.79 & 0.17 & -6.13 & -5.46 & 1149.04 & 1 & $<0.001$ \\
\hline
\end{tabular}

Table 4. Percentage speed-reducing effect of humps compared with the posted speed limit $(30 \mathrm{~km} / \mathrm{h})$ in daylight and darkness.

\begin{tabular}{ccc}
\hline Humps & \% Speed Reduction in Daylight & \% Speed Reduction in Darkness \\
\hline All humps & 20.7 & 21.3 \\
Hump 1 & 24.0 & 24.8 \\
Hump 2 & 9.3 & 9.9 \\
Hump 3 & 26.6 & 29.3 \\
\hline
\end{tabular}

The SED analysis showed that the three hump environments were visually perceived in a similar way in most regards, confirming hypothesis $\mathrm{V}$. The environments were perceived as neither very pleasant nor unpleasant, and all three were assessed as rather low in originality, suggesting that they represent very common types of environment. There was no significant difference between hump environments in terms of perceived complexity, unity, enclosedness, potency, and affection of the environment, but there were significant differences between hump environments in terms of perceived pleasantness, originality, and social status (Table 5 and Figure 5). The order of presentation of the humps in the questionnaire was shown to have a significant effect on answers relating to pleasantness, complexity, and potency. Pleasantness was rated higher for Hump 1 than Hump 2 (Table 5 and Figure 5). Originality and social status were rated lower for Hump 3 than Humps 1 and 2 (Table 5 and Figure 5). 


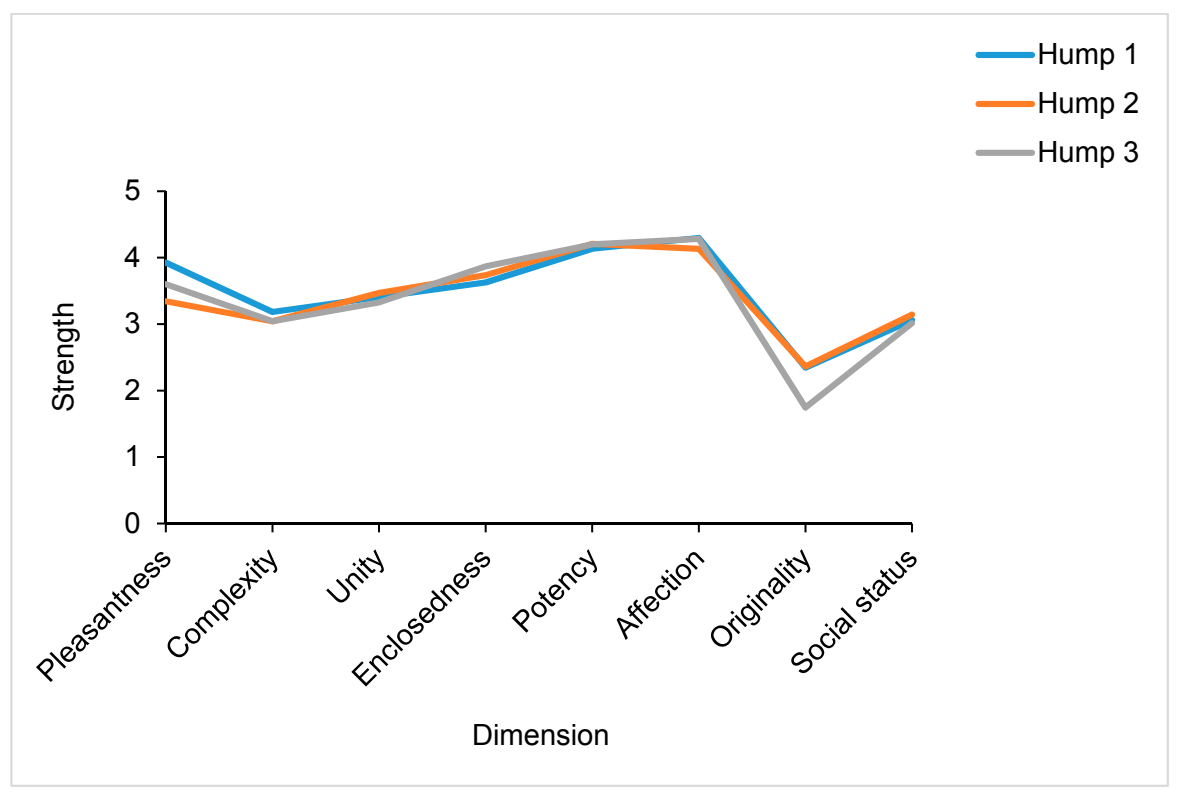

Figure 5. Mean values per hump of the eight different dimensions in the Semantic Environmental Description (SED). Y-axis shows the strength for each dimension $(0=$ smallest, $5=$ largest $)$.

Table 5. Results of two-way ANOVA (analysis of variance) of the eight dimensions in Semantic Environmental Description (SED), testing effects of humps and order of hump presentation in the questionnaire. $\mathrm{df}=$ degrees of freedom, $\mathrm{F}=\mathrm{F}$ value, $p=$ significance level.

\begin{tabular}{|c|c|c|c|c|c|}
\hline \multicolumn{6}{|c|}{ Tests of between-Subjects Effects } \\
\hline Source & Type III Sum of Squares & Df & Mean Square & $\mathbf{F}$ & $p$ \\
\hline \multicolumn{6}{|l|}{ Pleasantness } \\
\hline Corrected model & 17.1 & 8 & 2.1 & 3.1 & 0.004 \\
\hline Intercept & 1472.3 & 1 & 1472.3 & 2114.7 & 0.000 \\
\hline Hump & 6.2 & 2 & 3.1 & 4.4 & 0.014 \\
\hline Order & 9.5 & 2 & 4.7 & 6.8 & 0.002 \\
\hline Hump $\times$ Order & 1.2 & 4 & 0.3 & 0.4 & 0.795 \\
\hline Error & 75.2 & 108 & 0.7 & & \\
\hline Total & 1621.6 & 117 & & & \\
\hline Corrected total & 92.3 & 116 & & & \\
\hline \multicolumn{6}{|l|}{ Complexity } \\
\hline Corrected model & 7.1 & 8 & 0.9 & 2.0 & 0.059 \\
\hline Intercept & 1100.5 & 1 & 1100.5 & 2417.0 & 0.000 \\
\hline Hump & 0.2 & 2 & 0.1 & 0.2 & 0.832 \\
\hline Order & 4.2 & 2 & 2.1 & 4.7 & 0.012 \\
\hline Hump $\times$ Order & 2.3 & 4 & 0.6 & 1.3 & 0.287 \\
\hline Error & 49.2 & 108 & 0.5 & & \\
\hline Total & 1171.7 & 117 & & & \\
\hline Corrected total & 56.3 & 116 & & & \\
\hline \multicolumn{6}{|l|}{ Unity } \\
\hline Corrected model & 6.3 & 8 & 0.8 & 0.5 & 0.841 \\
\hline Intercept & 1325.7 & 1 & 1325.7 & 869.3 & 0.000 \\
\hline Hump & 0.4 & 2 & 0.2 & 0.1 & 0.868 \\
\hline Order & 4.8 & 2 & 2.4 & 1.6 & 0.213 \\
\hline Hump $\times$ Order & 1.1 & 4 & 0.3 & 0.2 & 0.945 \\
\hline Error & 164.7 & 108 & 1.5 & & \\
\hline Total & 1523.2 & 117 & & & \\
\hline Corrected total & 171.0 & 116 & & & \\
\hline
\end{tabular}


Table 5. Cont.

\begin{tabular}{|c|c|c|c|c|c|}
\hline \multicolumn{6}{|c|}{ Tests of between-Subjects Effects } \\
\hline Source & Type III Sum of Squares & Df & Mean Square & $\mathbf{F}$ & $p$ \\
\hline \multicolumn{6}{|l|}{ Enclosedness } \\
\hline Corrected Model & 5.9 & 8 & 0.7 & 1.1 & 0.393 \\
\hline Intercept & 1596.1 & 1 & 1596.1 & 2304.9 & 0.000 \\
\hline Hump & 1.1 & 2 & 0.6 & 0.8 & 0.449 \\
\hline Order & 3.3 & 2 & 1.6 & 2.4 & 0.099 \\
\hline Hump $\times$ Order & 1.5 & 4 & 0.4 & 0.6 & 0.694 \\
\hline Error & 74.8 & 108 & 0.7 & & \\
\hline Total & 1724.1 & 117 & & & \\
\hline Corrected total & 80.7 & 116 & & & \\
\hline \multicolumn{6}{|l|}{ Potency } \\
\hline Corrected model & 1.6 & 8 & 0.2 & 0.9 & 0.51 \\
\hline Intercept & 1982.1 & 1 & 1982.1 & 8978.1 & 0.000 \\
\hline Hump & 0.1 & 2 & 0.1 & 0.3 & 0.716 \\
\hline Order & 1.4 & 2 & 0.7 & 3.3 & 0.042 \\
\hline Hump $\times$ Order & 0.0 & 4 & 0.0 & 0.0 & 0.996 \\
\hline Error & 23.8 & 108 & 0.2 & & \\
\hline Total & 2071.3 & 117 & & & \\
\hline Corrected total & 25.5 & 116 & & & \\
\hline \multicolumn{6}{|l|}{ Affection } \\
\hline Corrected model & 4.8 & 8 & 0.6 & 1.1 & 0.376 \\
\hline Intercept & 1989.2 & 1 & 1989.2 & 3583.5 & 0.000 \\
\hline Hump & 0.7 & 2 & 0.4 & 0.6 & 0.53 \\
\hline Order & 3.2 & 2 & 1.6 & 2.9 & 0.062 \\
\hline Hump $\times$ Order & 1.0 & 4 & 0.2 & 0.4 & 0.783 \\
\hline Error & 60.0 & 108 & 0.6 & & \\
\hline Total & 2163.3 & 117 & & & \\
\hline Corrected total & 64.8 & 116 & & & \\
\hline \multicolumn{6}{|l|}{ Originality } \\
\hline Corrected model & 11.9 & 8 & 1.5 & 3.5 & 0.001 \\
\hline Intercept & 526.6 & 1 & 526.6 & 1255.7 & 0.000 \\
\hline Hump & 8.3 & 2 & 4.2 & 9.9 & 0.000 \\
\hline Order & 0.9 & 2 & 0.5 & 1.1 & 0.344 \\
\hline Hump $\times$ Order & 1.1 & 4 & 0.3 & 0.7 & 0.608 \\
\hline Error & 45.3 & 108 & 0.4 & & \\
\hline Total & 595.6 & 117 & & & \\
\hline Corrected total & 57.2 & 116 & & & \\
\hline \multicolumn{6}{|l|}{ Social status } \\
\hline Corrected model & 0.05 & 8 & 0.0 & 3.3 & 0.002 \\
\hline Intercept & 83.4 & 1 & 83.4 & 48872.9 & 0.000 \\
\hline Hump & 0.0 & 2 & 0.0 & 8.7 & 0.000 \\
\hline Order & 0.0 & 2 & 0.0 & 0.8 & 0.442 \\
\hline Hump $\times$ Order & 0.0 & 4 & 0.0 & 0.9 & 0.456 \\
\hline Error & 0.2 & 108 & 0.0 & & \\
\hline Total & 87.0 & 117 & & & \\
\hline Corrected total & 0.2 & 116 & & & \\
\hline
\end{tabular}

\section{Discussion}

This study showed that vehicle speed at the control location was negligibly higher in daylight than during the hours of darkness, but that the speed-reducing effect of humps was similar between daylight and darkness. The speed-reducing effect was significantly different between the hump that happened to have the lowest luminance (Hump 2) and the other two humps. However, this study 
could not reveal any significant differences in vehicle speed that are attributable to light conditions per se.

At the control location, driving speed was only slightly higher in daylight than during the hours of darkness, while the variation in speed was clearly higher during late night driving. No speed radar can accurately differentiate between speeds that differ by only $0.3 \mathrm{~km} / \mathrm{h}$, which was the difference that we found between daylight and darkness, so the speed difference can be considered to be negligible. Overall, mean values and the 50th percentile revealed that the speed was still around the posted speed limit during both daylight and darkness. However, speed at the 85 th percentile $(36 \mathrm{~km} / \mathrm{h})$ was high enough to justify speed-reducing measures along the road, where vulnerable road users may mix with vehicular traffic, in order to keep vehicle speeds at or below $30 \mathrm{~km} / \mathrm{h}$. The wide variation in vehicle speed during the hours of darkness can perhaps be explained by the influence of conditions affecting visibility, but also by human factors, such as drink-driving, i.e., factors known to cause an increased risk of night-time collisions. Furthermore, the driver composition may change at night-time, e.g., with an increased presence of young male drivers, who may drive faster [24]. In this study, we expect the traffic to be mainly residential, but cannot rule out the possibility of increased presence of young male drivers in night-time. It is difficult to compare mean vehicle speed with that reported in previous studies, since they often refer to roads with much higher posted speed limits (cf. [22-24]).

Our results showed that the humps in this study had a mean speed-reducing effect of $20 \%$ compared with the posted speed limit during both daylight and darkness, but also that there were large differences in speed reduction between the three speed humps, resulting in a speed-reducing effect of 9-29\% when compared with the posted speed limit. The speed-reducing effects of humps may vary between posted speed limits and site conditions and may also be limited in time and space. In this study, the bumps resulted in an 85th percentile of speed that was on average $29 \mathrm{~km} / \mathrm{h}$, as compared with $36 \mathrm{~km} / \mathrm{h}$ for the 85 th percentile at the control location. This can be interpreted as indicating that speed humps are an effective way of indirectly preventing fatal accidents by reducing speed. However, we measured vehicle speed at $5 \mathrm{~m}$ before the hump and it has been shown that speed-reducing effects take place 20-30 m before and after speed-reducing measures [4]. Therefore, we cannot rule out the possibility that speed acceleration took place after vehicles passed the humps, although speed humps are generally placed at several locations along the road in order to minimise acceleration effects in between (see Figure 1).

The speed humps had differing speed-reducing effects, which could be due to luminance since the speed hump with the lowest luminance also showed the least speed-reducing effect. The speed hump resulting in the smallest speed-reducing effects (hump 2) had a light pole situated behind the raised hump and the illumination and visibility of the hump were therefore low for approaching drivers. Yet, it is unknown if these differences in vehicle speed are attributed to light conditions per se. In fact, the lack of difference in vehicle speed between daylight and darkness for hump 2 may indicate that the luminance of the hump was less important in controlling the speed and that it is possible that other factors, such as road geometry, may have a certain influence on the speed reduction. Furthermore, the location where the study took place is in a residential area, so we assume that most of the drivers passing the humps are familiar with the road and thus adapted their driving behaviour to the presence of the speed humps. However, it is likely that if you are unfamiliar with area, the luminance and visibility of the humps may be of higher importance for the speed-reducing effect.

Road lighting should be installed in a way that increases the visibility of speed-reducing measures for drivers and the luminance measurements in this study suggests that light poles should be placed directly above or in front of speed-reducing measures to increase their visibility. However, the hump that showed the largest speed-reduction effect between daylight and darkness did not have the highest luminance. If fact, vehicle speed responses to humps were not significantly different between daylight and darkness. Since darkness reduces visual performance a speed adjustment is required to compensate for the reduced reaction time, or else, the risk for traffic accidents will increase. However, similar to this study, other studies have also showed that vehicle speed tend to be similar during 
daylight and darkness $[25,26]$, supporting the theory that drivers fail to compensate for their reduced visual recognition in low light and misjudge their visual ability [33-35]. Due to these circumstances, it is important to ensure that the road lighting increases the visual performance for the drivers.

The SED showed that perceived differences between the hump environments could not explain differences in driving behaviour between the humps and the originality for hump road environments was generally rated very low. Moreover, the road environment between humps was perceived as very similar. Thus, if there was any effect of the surrounding environments on driving behaviour, it was not based on the perceived environmental differences, but other factors. One such other factor could be the distance to an intersection or the geometric design. Hump 2 was closest to an intersection (the intersection was located after the hump) and showed greater speed responses. However, if the intersection had affected driving behaviour, vehicles would have been expected to drive more slowly to prepare for turning or to allow for oncoming turning vehicles. This was not the case.

Another difficulty in analysing the effects of speed humps is that speed data are influenced by confounding effects from the road environment, traffic volume, and traffic patterns. While only free-flowing vehicles were included in the speed data in this study, which excluded some effects of the traffic volume, there might still be effects of traffic patterns. This is due to different driving patterns arising in vehicle clusters and because driving habits can vary between different times of the day. In this study, there were no significant differences between daylight and darkness, but differences in driving patterns between daylight and darkness have been shown in other studies, where a higher speed during the hours of darkness was attributed to a switch to faster drivers at night, simultaneously with a decrease in the proportion of slower drivers $[23,24]$. The speed measurements in the present study showed signs of faster driving during the hours of darkness, but there were small differences between the mean values of speed in daylight and darkness, supporting that the speed differences are rather negligible.

Further studies under more controlled circumstances are needed to control for the effects of the geometrical design and driving patterns at different times of the day, and to determine before/after effects of installing speed humps. The control location and humps were situated along the same residential road in the present study. In future work, the humps should be moved to rule out the effects of the longitudinal interval between consecutive humps. Various distances between road lighting and the speed-reducing measures should also be examined, since pole spacing in practice can vary much (e.g., $20-35 \mathrm{~m}$ on residential roads) when compared to that tested in this study ( $\sim 30 \mathrm{~m})$.

\section{Conclusions}

Speed humps reduced driving speed by $20 \%$ as compared with a control location. Speed hump effect was not significantly different between daylight and darkness. The speed reduction for three different speed humps varied between $9 \%$ and $29 \%$. In this study, the LED road lighting that was placed directly above or in front of the hump achieved the highest luminance.

Supplementary Materials: The following are available online at http://www.mdpi.com/2313-576X/4/1/10/s1, Figure S1: The total number of vehicles summed up per hour at the control location.

Acknowledgments: This study was funded by the Swedish Energy Agency through its research programme on energy-efficient lighting, part II (2012-003200), project number 36232-1. The work took place with the kind cooperation of Thomas Dottman and Ebrahim K. Zadeh, Botkyrka municipality, and Lotta Frejd Malmqvist and Niklas Thell from NVF, the Swedish national society for road safety. Staffan Dahlberg and Anders Genell are acknowledged for their support.

Author Contributions: Annika K. Jägerbrand planned and carried out the experiment, statistical analyses, prepared diagrams and was main author of the paper. Maria Johansson and Thorbjörn Laike contributed to the writing and commented on the manuscript.

Conflicts of Interest: The authors declare no conflict of interest. The founding sponsors had no role in the design of the study; in the collection, analyses, or interpretation of data; in the writing of the manuscript, and in the decision to publish the results. 


\section{References}

1. Johansson, R. Vision zero-Implementing a policy for traffic safety. Saf. Sci. 2009, 47, 826-831. [CrossRef]

2. Anderson, R.W.G.; McLean, A.J.; Farmer, M.J.B.; Lee, B.H.; Brooks, C.G. Vehicle travel speeds and the incidence of fatal pedestrian crashes. Accid. Anal. Prev. 1997, 29, 667-674. [CrossRef]

3. Rosén, E.; Stigson, H.; Sander, U. Literature review of pedestrian fatality risk as a function of car impact speed. Accid. Anal. Prev. 2011, 43, 25-33. [CrossRef] [PubMed]

4. Pau, M.; Angius, S. Do speed bumps really decrease traffic speed? An italian experience. Accid. Anal. Prev. 2001, 33, 585-597. [CrossRef]

5. Johnson, L.; Nedzesky, A.J. A Comparative Study of Speed Humps, Speed Slots and Speed Cushions; U.S. Department of Transportation, Federal Highway Administration, Report. 2004. Available online: http: / / safety.fhwa.dot.gov/speedmgt/ref_mats/fhwasa1304/Resources3/26\%20-\%20A\%20Comparative\% 20Study\%20of\%20Speed\%20Humps, \%20Speed\%20Slots\%20and\%20Speed\%20Cushions.pdf (accessed on 21 December 2017).

6. ITE. Traffic Calming Measures—Speed Hump. Available online: http://www.ite.org/traffic/hump.asp (accessed on 31 December 2017).

7. Bassani, M.; Dalmazzo, D.; Riviera, P.P. Field Investigation on the Effects on Operating Speed Caused by trapezoidal humps. In Proceedings of the Transportation Research Board 90th Annual Meeting, Washington, DC, USA, 23-27 January 2011; Transportation Research Board: Washington, DC, USA, 2011.

8. Hallmark, S.; Knapp, K.; Thomas, G.; Smith, D. Temporary Speed Hump Impact Evaluation; CTRE Project 00-73; Centre for Transportation Research and Education, Iowa State University: Ames, IA, USA, 2002.

9. Sumner, R.; Baguley, C. Speed Control Humps on Residential Roads; TRRL Laboratory Report 878; Transport and Road Research Laboratory: Wokingham, UK, 1979.

10. Barbosa, H.M.; Tight, M.R.; May, A.D. A model of speed profiles for traffic calmed roads. Transp. Res. Part A 2000, 34, 103-123. [CrossRef]

11. Salau, T.A.O.; Adeyefa, A.O.; Oke, S.A. Vehicle speed control using road bumps. Transport 2004, 19, 130-136.

12. Molan, A.M.; Kordani, A.A. Optimization of speed hump profiles based on vehicle dynamic performance modeling. J. Transp. Eng. 2014, 140, 04014035. [CrossRef]

13. Tester, J.M.; Rutherford, G.W.; Wald, Z.; Rutherford, M.W. A matched case-control study evaluating the effectiveness of speed humps in reducing child pedestrian injuries. Am. J. Public Health 2004, 94, 646-650. [CrossRef] [PubMed]

14. Rothman, L.; Macpherson, A.; Buliung, R.; Macarthur, C.; To, T.; Larsen, K.; Howard, A. Installation of speed humps and pedestrian-motor vehicle collisions in toronto, canada: A quasi-experimental study. BMC Public Health 2015, 15, 774. [CrossRef] [PubMed]

15. Elvik, R. Meta-analysis of evaluations of public lighting as accident countermeasure. Transp. Res. Rec. 1995, 1485, 112-123. Available online: http:/ / onlinepubs.trb.org/Onlinepubs/trr/1995/1485/1485-015.pdf (accessed on 9 March 2018).

16. Johansson, O.; Wanvik, P.O.; Elvik, R. A new method for assessing the risk of accident associated with darkness. Accid. Anal. Prev. 2009, 41, 809-815. [CrossRef] [PubMed]

17. Wanvik, P.O. Effects of road lighting: An analysis based on dutch accident statistics 1987-2006. Accid. Anal. Prev. 2009, 41, 123-128. [CrossRef] [PubMed]

18. Beyer, F.R.; Ker, K. Street lighting for preventing road traffic injuries. Cochrane Database Syst. Rev. 2009. [CrossRef] [PubMed]

19. Sullivan, J.M.; Flannagan, M.J. Determining the potential safety benefit of improved lighting in three pedestrian crash scenarios. Accid. Anal. Prev. 2007, 39, 638-647. [CrossRef] [PubMed]

20. Elvik, R.; Vaa, T. The Handbook of Road Safety Measures; Emerald Group Publishing Limited: Bingley, UK, 2004.

21. Monsere, C.M.; Fischer, E.L. Safety effects of reducing freeway illumination for energy conservation. Accid. Anal. Prev. 2008, 40, 1773-1780. [CrossRef] [PubMed]

22. Möller, S. Väglag-Trafikflöde-Hastighet. En Studie av Nyttan Med att ta Hänsyn till Väglaget vid Bortfallskomplettering av Trafikflöde och Hastighet; VTI Meddelande 794; The Swedish National Road and Transport Research Institute: Linköping, Sweden, 1996; pp. 1-37.

23. Assum, T.; Bjørnskau, T.; Fosser, S.; Sagberg, F. Risk compensation-The case of road lighting. Accid. Anal. Prev. 1999, 31, 545-553. [CrossRef] 
24. Bassani, M.; Mutani, G. Effects of environmental lighting conditions on operating speeds on urban arterials. Transp. Res. Rec. 2012, 2298, 78-87. [CrossRef]

25. Quaium, R.B.A. A Comparison of Vehicle Speed at Day and Night at Rural Horizontal Curves. Master's Thesis, Virginia Polytechnic Institute and State University, Blacksburg, VA, USA, 2010.

26. Jägerbrand, A.K.; Sjöbergh, J. Effects of weather conditions, light conditions, and road lighting on vehicle speed. SpringerPlus 2016, 5, 505. [CrossRef] [PubMed]

27. Jägerbrand, A.K. New framework of sustainable indicators for outdoor led (light emitting diodes) lighting and ssl (solid state lighting). Sustainability 2015, 7, 1028-1063. [CrossRef]

28. Kuhn, L.; Johansson, M.; Laike, T.; Govén, T. Residents perceptions following retrofitting of residential area outdoor lighting with leds. Light. Res. Technol. 2013, 45, 568-584. [CrossRef]

29. Tashiro, T.; Kawanobe, S.; Kimura-Minoda, T.; Kohko, S.; Ishikawa, T.; Ayama, M. Discomfort glare for white led light sources with different spatial arrangements. Light. Res. Technol. 2015, 47, 316-337. [CrossRef]

30. Küller, R. Semantisk Miljö Beskrivning (SMB); Psykologiförlaget AB, Liber Tryck: Stockholm, Sweden, 1975; pp. 1-44.

31. Vogel, K. What characterizes a "free vehicle" in an urban area? Transp. Res. Part F 2002, 5, 313-327. [CrossRef]

32. Bozdogan, H. Model selection and akaike's information criteria (aic): The general theory and its analytical extensions. Psychometrika 1987, 52, 345-370. [CrossRef]

33. Leibowitz, H.W.; Owens, D.A.; Tyrrell, R.A. The assured clear distance ahead rule: Implications for nighttime traffic safety and the law. Accid. Anal. Prev. 1998, 30, 93-99. [CrossRef]

34. Owens, D.A.; Tyrrell, R.A. Effects of luminance, blur, and age on nighttime visual guidance: A test of the selective degradation hypothesis. J. Exp. Psychol. 1999, 5, 115-128. [CrossRef]

35. Owens, D.A.; Wood, J.M.; Owens, J.M. Effects of age and illumination on night driving: A road test. Hum. Factors 2007, 49, 1115-1131. [CrossRef] [PubMed]

(C) 2018 by the authors. Licensee MDPI, Basel, Switzerland. This article is an open access article distributed under the terms and conditions of the Creative Commons Attribution (CC BY) license (http://creativecommons.org/licenses/by/4.0/). 